\title{
Mothers' Awareness toward Chickenpox Disease for Preschool Children at Nursery School in Benha City
}

\author{
Seham M. Amer, Karima A. El-Sayed, Salwa I. Mahmoud
}

\begin{abstract}
Background, Quality of nursing work life and staff nurses' commitment are two issues that should be given paramount importance by nurse managers in any hospital due to the positive influence on nurses' satisfaction, retention, performance and productivity. The purpose of the study was to identify relation between quality of nursing work life and staff nurses' commitment in critical care units at Benha University Hospital. Descriptive correlational design was utilized to meet the purpose of this study. Setting this study was conducted at Benha University Hospital. Study sample was composed of 216 staff nurses. One instrument was used for data collection (Quality of nursing work life and staff nurses' commitment questionnaire sheet). Results showed that $57.4 \%$ of staff nurses had moderate level of quality of nursing work life, $55.6 \%$ of staff nurses had moderate level of staff nurses 'commitment. The study concluded that there was a significant positive correlation between quality of nursing work life and staff nurses' commitment. The study Recommended further research for assessing the effectiveness of specific interventions in improving quality of work life among nurses.
\end{abstract}

Keywords: Quality of Nursing Work Life

\section{Introduction:}

Staff nurses can be viewed as "the back bone of the hospital" given that they are the first component of patient care. So, it is important to ensure their well-being and work-life balance to maintain nursing quality as well as quality of healthcare facilities. Nursing is stressful and demanding occupation with long and irregular hours, health and safety hazards, heavy workload, patient-related stressors, low wages, and sleep disruption. Nurses are amongst the staff whose lives are fully affected by the quality of work life (QWL) as a consequence of dynamic changes in work environment (Heinen et al., 2016; Bogossian et al., 2017). Role of nurses in taking care of patients in hospitals is vital, especially the staff nurses who Work in the critical care units. Their work is more complex than nurses who work in other units because they take care of patients who considered critically ill and have life risk. Staff nurses deal with difficulties related to the technical complexity of patient care, and are exposed to the highmaintenance demands of patients, their families, doctors, and institutions, all of which can put nurses under considerable stress (Cho, 2017).

Issues such as QWL and organizational commitment (OC) among staff nurses are of great importance due to the crucial role in improving the efficiency of staff nurses, improving staff nurses' efficiency gets through improving working conditions and staff nurses' integration with the work place. And it can also increase job satisfaction, 
work performance and the quality of care. But, it can decrease absenteeism, stress, burnout and turnover intention (Chen and Wang, 2017; Huang et al., 2017).

Quality of nursing work life (QNWL) is a complex, multidim-ensional concept that has been defined in different ways by different researchers. However, a clear definition of QNWL remains lacking. QNWL refers to the staff nurses' satisfaction with working life as well as personal life while the hospital goals are achieved. It is a comprehensive concept including various aspects of work itself and the work environment. It enumerates the impact of the work place on job satisfaction, content/discontent with home life, overall satisfaction with life, personal happiness, and mental wellbeing (Zhao et al., 2016;

Boonrod, 2017).

Quality of nursing work life influenced by some factors that can categorized into four dimensions: Work life/home life, work design, work context, work world. Work life/home life dimension describes the nurses' life experience at work and home or the degree to which staff nurse is engaged in and satisfied with, in equal measure, the work and non-work roles (Azeem and Akhtar, 2016).

Work design dimension describes the real work the staff nurses do. But, work context dimension describes the effect of workplace on staff nurses and patients, while work world dimension describes vast social impacts as well as the effects of changes on the functioning of nursing profession. Nurses as a large group of health care providers who handle human lives should have an appropriate work life in order to take care of the patients well (O'Brien-Pallas and Baumann, 2016).
Staff nurses' commitment is the situation where staff nurses develop loyalty or commitment towards the working place. Its definitions have been presented in various sources . Management experts define commitment as an attitude or orientation toward the work place. Staff nurses' commitment as an attitude includes a strong desire to stay in the work place, exert excessive effort for the hospital, and a strong belief in accepting its values and goals. So, it refers to the links between the work place and the staff (Zeineldin and Abdel Rahman, 2016; Krestaniti and Prezerakos, 2017).

According to Meyer and Allen, (1990) model pointed to that commitment includes affective, continuance and normative dimensions. Affective commitment is the kind of commitment that causes staff nurses to become closer to the work place emotionally and feel happy because of being part of the hospital. While continuance commitment includes a value-based commitment to the hospital and staff nurse continue to be a member in the hospital and commitment because of personal expectations and profits. As it is called rational continuance, it is the awareness of staff nurses for the cost of leaving from hospital (Seyedin et al., 2017; Larber and Savis, 2017).

Finally normative commitment: refers to staff nurses' feelings based on the need to stay in their work setting, preferring to stay on the hospital because of past relations. This commitment consists of a compulsory basis. Staff nurse's feelings are because of the trainings or good relations are the cause of this commitment. In other words since staff nurse beliefs that to stay in the hospital is some kind of responsibility (Nogueras, 2016)

\section{Purpose:}

To identify the relation between quality of nursing work life and staff nurses' 
commitment in critical care units at

Benha University Hospital.

\section{Research Questions}

1-What are the levels of quality of nursing work life among staff nurses in critical care units?

2-What are the levels of staff nurses' commitment in critical care units?

3 - Is there relation between quality of nursing work life and staff nurses' commitment in critical care units?

\section{Methods:}

1- Design: Descriptive correlational design was used for carrying out this study.

2-Setting: The study was carried out at Benha University Hospital in Critical Care Units.

\section{3-Sampling:}

All staff nurses working in the above mentioned setting were eligible to participate in the study. Their total number was 216.

4-Instruments: One instrument was used for data collection

Data of the present study was collected by using one instrument (quality of nursing work life and staff nurses' commitment questionnaire sheet).

Part I: concerned with personal data of staff nurses such as age, gender, marital status, level of education, unit and years of experience.

Part II: Quality of nursing work life scale: It was developed by Khani et al., (2008) and was modified by the researcher. This part intended to assess quality of nursing work life among staff nurses. It was consisted of 42 items divided into four dimensions; work life/ home life (7 items), work design (10 items), work context (20 items) and work world (5 items). $(\alpha=0.862)$

\section{Scoring system:}

\begin{tabular}{|l|c|}
\hline \multicolumn{1}{|c|}{ Scoring items } & Scores \\
\hline Strongly disagree & 1 \\
\hline Disagree & 2 \\
\hline Uncertain & 3 \\
\hline Agree & 4 \\
\hline Strongly agree & 5 \\
\hline
\end{tabular}

Part III: Staff nurses' commitment questionnaire: It was developed by Allen \& Meyer, (1990) and was modified by the researcher to assess staff nurses' commitment toward their hospital. It included 24 items divided into three dimensions; affective commitment (8 items), continuance commitment (8 items) and normative commitment ( 8 items). $(\alpha=0.875)$

Scoring system:

\begin{tabular}{|l|l|}
\hline Scoring items & Scores \\
\hline Strongly disagree & 1 \\
\hline Disagree & 2 \\
\hline Uncertain & 3 \\
\hline Agree & 4 \\
\hline Strongly agree & 5 \\
\hline
\end{tabular}

Pilot study: A pilot study was carried out in June 2017 to ascertain the clarity and applicability of the study tools. 22 staff nurses were included in the pilot study representing $10 \%$ of total study subjects. It has also served in estimating the time needed for filling the tools. It ranged between 15-20 minutes. No modification was needed. The pilot included in the study.

Ethical Considerations: Oral informed consents were obtained from the participants. They were informed about their rights to refuse or withdraw from the study with no consequences. They were reassured about the anonymity and confidentiality of the information collected, and would be used only for the purpose of scientific research. No harmful maneuvers were performed or used and no foreseen hazards were anticipated from conducting the study on participants

\section{Procedure:}

1-This phase started from March 2017 to June 2017. It included the following: Reviewing the national and international related literature using journals, periodicals, textbooks, internet and theoretical knowledge of the various aspects concerning the topic of the study for modifying the tools and 
translating the tools into Arabic language and back translation to check its accuracy. Tools validity: face and content of study tools were validated by jury group consisted of five experts from nursing administration (2 assistant professors from Tanta University, one professor and two lecturers from Menofia University). It took one month (May) 2017.

2-Data collection took about three months from beginning of July 2017 to end of September 2017. The researcher met staff nurses and explained the aim and the nature of the study and the method of filling questionnaire. This was done individually or through group meetings. The researcher distributed the questionnaire sheets to the participated staff nurses to fill it in work times which determined before with head nurse of each unit according to type of work and work load. The number of collected questionnaire from staff nurses per day ranged from 5 to 15 sheets. It took from 15 to 20 minutes to complete the questionnaire sheet. Data collected three days /week in Saturday, Monday and Thursday from 10 am to 1 $\mathrm{pm}$ in the presence of the researcher to clarify any ambiguity.

3- An official letter requesting permission to conduct the study was issued from the Dean of faculty of nursing Benha University that were sent to the director of the hospital explaining the aim of the study. Then, the researcher met the hospital administrator, assured complete confidentiality of the obtained information and the study would not affect in any way the work.

Data design: After completion of data collection, the data were organized and tabulated and statistical analysis was done using Statistical Package for the Social Sciences (SPSS) version (20.0). Data were presented using descriptive statistics in the form of frequencies and percentages for qualitative variables. Qualitative variables were compared using chi square test $\left(\mathbf{X}^{\mathbf{2}}\right)$ as the test of significance and correlation coefficient. Statistical significance level value was considered when $\mathrm{p}$ - value $<0.05$ and a highly significance level was considered when $\mathrm{p}$-value $<0.001$, while $\mathrm{p}$-value $>$ 0.05 indicates non-significant results.

\section{$\underline{\text { Results }}$}

Table (1): shows that half $(50.5 \%)$ of staff nurses age ranged between 20 to $<30$ years old with Mean \pm SD (31.42 \pm 6.85$)$. Regarding to gender and marital status, the majority $(93.5 \%$, $86.6 \%$ ) of them were females and married, respectively. In relation to Level of education, more than half $(56.5 \%)$ of them were diploma degree in nursing. Regarding to their years of experience less than half $(41.7 \%)$ of staff nurses had 10 to $<20$ years of experience.

Figure (1): illustrates that nearly one quarter $(22.2 \%)$ of staff nurses were distributed in ICU.

Figure (2): illustrates that more than half $(57.4 \%)$ of them had moderate level of quality of nursing work life.

Figure (3): illustrates that more than half $(55.6 \%)$ of them had moderate level of staff nurses 'commitment.

Table (2): shows correlation between quality of nursing work life and staff nurses' commitment. This result demonstrated that there was a significant positive correlation between quality of nursing work life and staff nurses' commitment.

Table (1): Frequency distribution of personal data of the studied staff nurses $(n=216)$ 
Relation between Quality of Nursing Work life and Staff Nurses' Commitment in Critical Care Units

\begin{tabular}{|c|c|c|}
\hline Personal data & Frequency & $\%$ \\
\hline \multicolumn{3}{|l|}{ Age in years } \\
\hline $20-<30$ & 109 & 50.5 \\
\hline $30-<40$ & 73 & 33.8 \\
\hline$\geq 40$ & 34 & 15.7 \\
\hline \multicolumn{3}{|c|}{$31.42 \pm 6.85$} \\
\hline \multicolumn{3}{|l|}{ Gender } \\
\hline Female & 202 & 93.5 \\
\hline Male & 14 & 6.5 \\
\hline \multicolumn{3}{|l|}{ Marital status } \\
\hline Single & 16 & 7.4 \\
\hline Married & 187 & 86.6 \\
\hline Widow & 10 & 4.6 \\
\hline Divorced & 3 & 1.4 \\
\hline \multicolumn{3}{|l|}{ Education } \\
\hline Diploma degree in nursing & 122 & 56.5 \\
\hline Associated degree in nursing & 52 & 24.1 \\
\hline Bacheloric degree in nursing & 42 & 19.4 \\
\hline \multicolumn{3}{|l|}{ Years of experience } \\
\hline $1-<10$ & 82 & 38 \\
\hline $10-<20$ & 90 & 41.7 \\
\hline $20-<30$ & 36 & 16.7 \\
\hline$\geq 30$ & 8 & 3.7 \\
\hline \multicolumn{3}{|c|}{$12.04 \pm 8.36$} \\
\hline
\end{tabular}

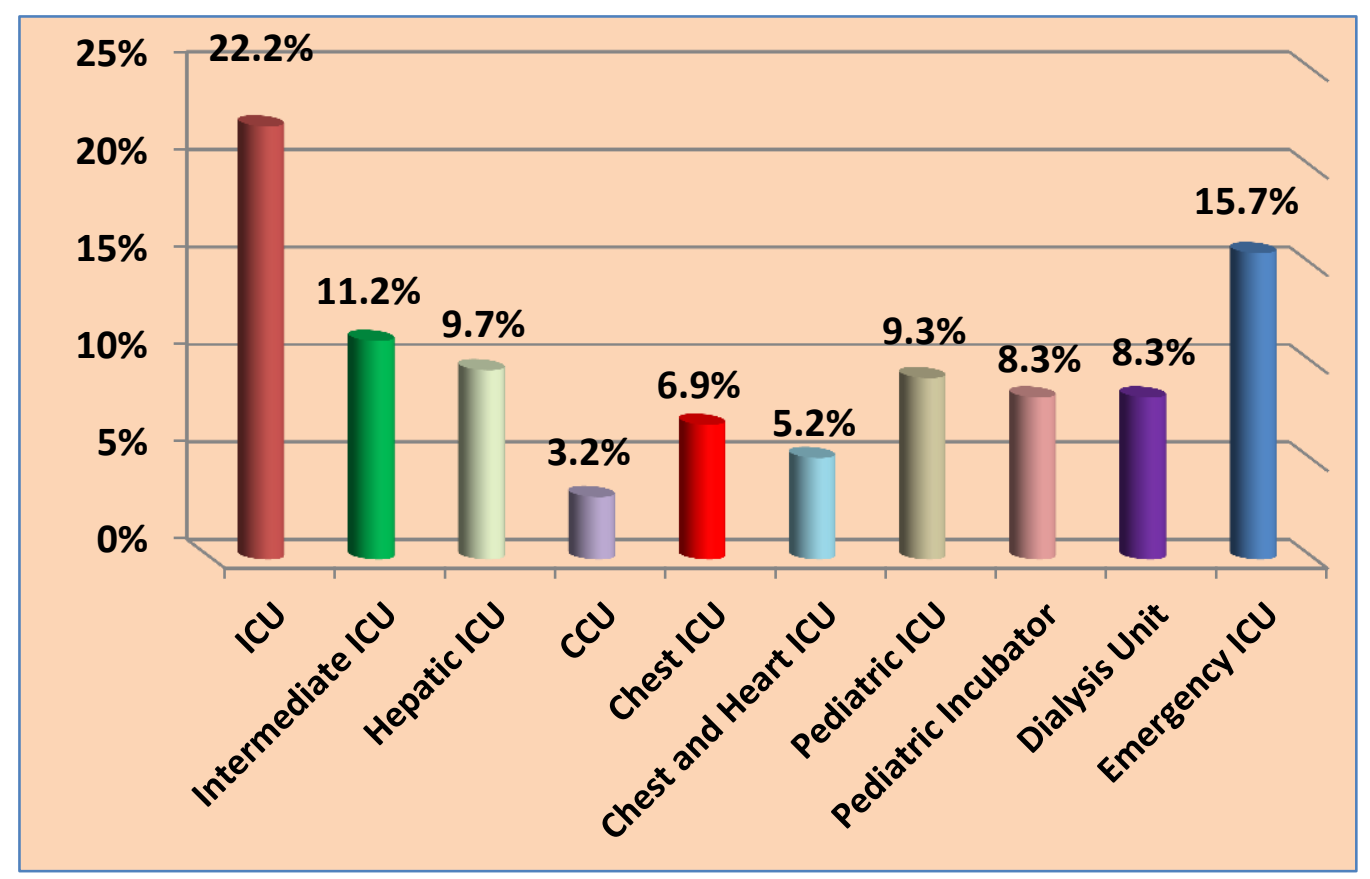

Figure (1): Distribution of staff nurses in Critical Care Units $(n=216)$ 


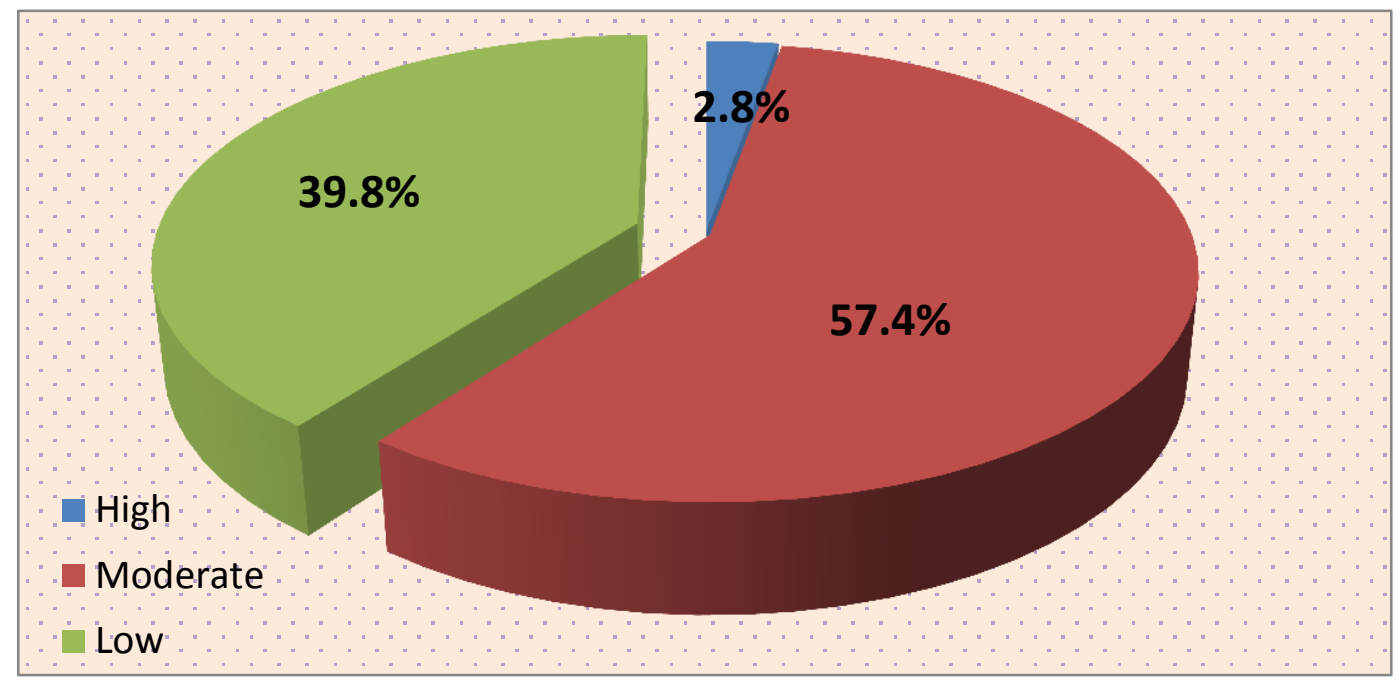

Figure (2): Levels of staff nurses' quality of nursing work life (n=216)

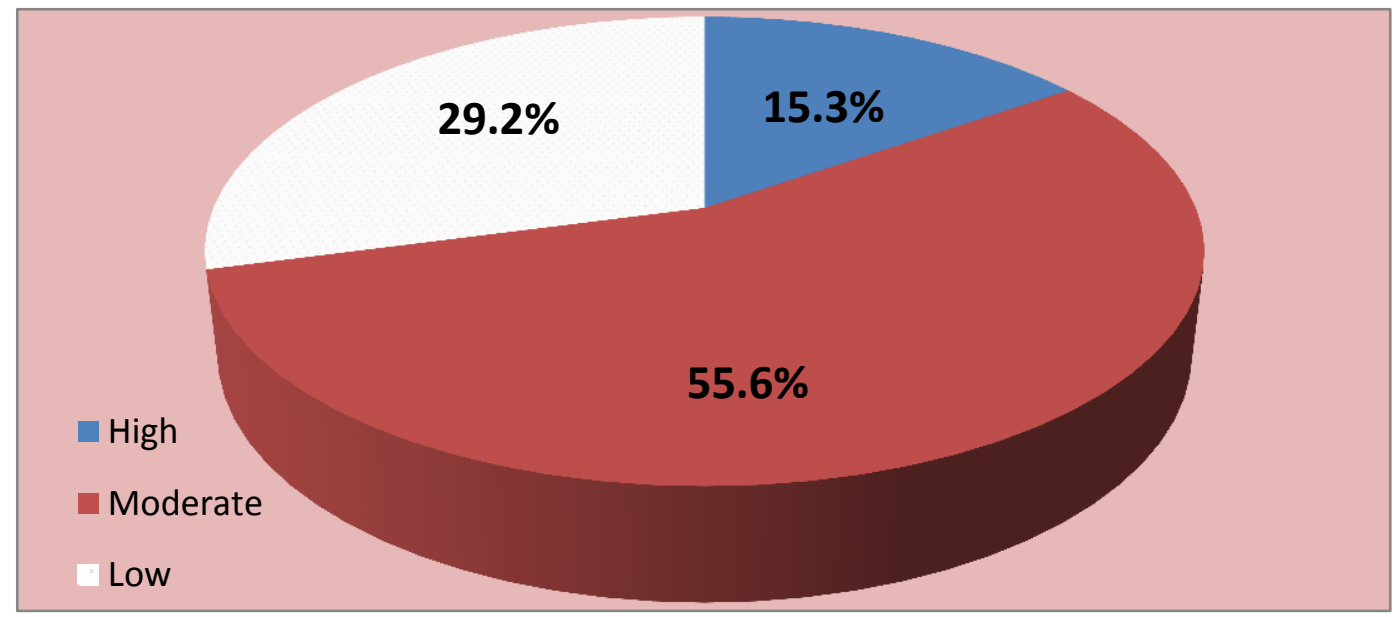

Figure (3): Levels of staff nurses' commitment $(n=216)$

Table (2) Correlation between quality of nursing work life and staff nurses' commitment $(\mathbf{n}=\mathbf{2 1 6})$

\begin{tabular}{|c|c|c|}
\hline \multirow{2}{*}{ Variables } & \multicolumn{2}{|c|}{ Quality of nursing work life } \\
\cline { 2 - 3 } & $\mathbf{r}$ & P value \\
\hline Staff nurses' commitment & $0.567^{* *}$ & .000 \\
\hline
\end{tabular}

Correlation is significant at the 0.01 level (2-tailed).

\section{Discussion:}

The purpose of the study was to identify relation between quality of nursing work life and staff nurses' commitment in critical care units at Benha University Hospital through assessing quality of nursing work life among staff nurses, identifying staff nurses' commitment, investigating relation between quality of nursing work life and staff nurses' commitment.
The results of the present study revealed that majority of staff nurses were distributed in ICU. This could be due to ICU characterized by excessive workload demands, presence of higher levels of patient acuity, more sophisticated use of technology based interventions, working in stressful environment and dealing with life-threatening health problems. This result matched with Valentine et al., (2013), who found that most of staff 


\section{Relation between Quality of Nursing Work life and Staff Nurses' Commitment in Critical \\ Care Units}

nurses were distributed in ICU (Figure 1).

The findings of the present study revealed that more than half of staff nurses had moderate level of quality of nursing work life. This could be due to staff nurses' moderate level towards their work life, including family needs, professional development, work environment, work conditions, public image of nursing and financial benefits. So, with increasing staff nurses perception toward quality of work life dimensions, the perception may be high (Figure 2).

This finding was consistent with Reyasi, (2013) and Falsa, (2017), who reported that the majority of nurses had a moderate level of working life quality. On the other hand, this result disagreement with El-Sayed and AbdelAleem, (2014), who showed that the minority of staff nurses had low quality of work life, while the majority of staff nurses had high quality of work life.

The results of the present study revealed that more than half of staff nurses had moderate level of staff nurses 'commitment. This could be due to the cost that staff nurses linked with leaving the hospital or on a perceived lack of alternative government employment opportunities or because of the past relationships they made with their colleagues in their hospital. For these reasons, they preferred staying in their work (Figure 3).

This finding was congruent with $\boldsymbol{E l}$ Demerdash et al., (2013), who concluded that three fourth of staff nurses had moderate level of total organizational commitment in intensive care units. Also, this result was agreement with Salah et al., (2014), illustrated that more than half of the studied nurses had moderate organizational commitment level. On the other hand, this result was inconsistent with Kebriaei et al., (2013), who showed that perception of organizational commitment of the studied sample was relatively high.
The present study revealed that there was a significant positive correlation between quality of nursing work life, its dimensions and staff nurses' commitment, its dimensions toward the hospital. This might be due to that perception of quality of work life has positive effects on staff and the hospital where working for as enhancing staff performance, decreasing staff abseentism and increasing organizational commitment. This mean when quality of nursing work life increased staff nurses' commitment toward the hospital increased (Table 2).

In the same context, this finding was congruent with Wilson and Laschinger, (2015), who found that the higher staff nurse's quality of work life, the more positive feelings about the hospital where staff nurse works for. It is assumed that if staff nurse is feeling positive about the hospital works for, this positive emotion results in organizational commitment. Also, this finding was agreement with Barzoki and Sarand, (2016), who reported that there was a significant and direct relationship with a high correlation between organizational commitment and quality of work life.

\section{Conclusion}

The result of present study was concluded that:

- Staff nurses had moderate level of quality of nursing work life.

- Staff nurses had moderate level of staff nurses 'commitment.

- There was a significant positive correlation between quality of nursing work life and staff nurses' commitment toward the hospital.

\section{Recommendations}

In the light of the findings obtained from the present study, the following points are recommended:

\section{- For staff nurses:}

- Making a supportive and friendly environment for all staff nurses.

- Staff nurses should be given an opportunity for participation in 
decisions that made by nurse manager and respecting their viewpoints.

- Balanced time schedule to assure workload distribution.

- Providing comfortable rooms for staff nurses.

- Staff nurses should be encouraged for educational growth in nursing to promote staff nurses' growth in their profession.

* For further research:

- Assessing the effectiveness of specific interventions in improving QWL among nurses.

- Establishing strategies to increase staff nurses' organizational commitment.

\section{References:}

Ahmadi, F. (2012): Relationship between quality of work life and organizational commitment in public organization in Kurdistan Province, Interdisciplinary Journal of Contemporary Research, 4(1), p.235.

Allen, N. \& Meyer, J. (1990): The measurement and antecedents of affective, continuance and normative commitment to the organization, Journal of Occupational Psychology, 1(1), pp.6-7.

Azeem, S. \& Akhtar, N. (2016): The influence of work life balance and job satisfaction on organizational commitment of healthcare employees, International journal of Human Resource Studies, 4(2), pp.19-20.

Barzoki, A. \& Sarand, V. (2016): Investigating the relationship between organizational justice, organizational commitment and staff's quality of work life, Journal of Management, 2(10), P.45.

Bogossian, F., Winters-Chang, P. \&Tuckett, A. (2017): The Pure Hard Slog that nursing is.: A Qualitative analysis of nursing work, Journal of Nursing Scholarship, 46(5), pp.377378.

Boonrod, W. (2017): Quality of working life: Perceptions of professional nurses at Phramongkutklao Hospital, Journal of Medicine, 9(2), p.9.

Chen, C. \& Wang, S. (2017): A study of job stress, quality of work life, organizational commitment and job satisfaction for nurses working in middle-level hospital operating rooms, Journal of Nursing Research, 17(3), pp. 199-200.

Cho, C. (2017): Factors affecting quality of work life among nurses working in Intensive Care Units, International Journal of Nursing, 8(9), pp. 2-3.

El-Demerdash, S., Basal, A. \& Aldeeb, G. (2013): The relationship between burnout and organizational commitment among nurses at Tanta university hospital, 2(6), pp.20-28.

El-Sayed, R. \& Abdel-Aleem, M. (2014): Quality of Work Life and Horizontal Violence among Staff Nurses, Medicine Journal of Cairo University, 82(1), p.860.

Fasla, n. (2017): A study on Quality of Work Life among Private Hospital Nurses, Journal of Management, 5(4), p.235.

Heinen, M., Van-Achterberg, T., Schwendimann, R., Zander, B., Matthews, A. \& Kózka, M., (2016): Nurses' intention to leave their profession: a cross sectional observational study in 10 European countries, International Journal of Nursing Studies, 50(2), P.84.

Huang, T., Lawler, J. \& Lei, C .(2017): The Effects of Quality of Work Life on Commitment and Turnover Intention, Social Behavior and Personality, an international journal, $35(6)$, p. 50.

Kebriaei, A., Rakhshaninejad, M., Afshari, Z. \& Mohseni, M. (2013): Psychological empowerment in Hospital Administrative staff predicts their organizational commitment, International Journal of Hospital Research, 2(4), p. 6. 
Khani, A., Jaafarpour, M. \& Dyrekvandmogadama, A. (2008): Quality of nursing work life, Journal of clinical and diagnostic research, 2(6), pp.1170-1171.

Krestaniti, E. \& Prezerako, S. (2017): Organizational commitment of the nursing personnel in a Greek national health system hospital, International Journal of Caring Sciences, 7(1), p.7.

Larber, M. \& Savis, S. (2017): Factors affecting nurses' organizational commitment, Obzornik zdravstvene Nege, 48(4), p. 301.

Morsy, M. \& Sabra, E. (2015): White, L., Duncan, G. \& Baumle, W. (2011): Foundation of Nursing, 3rd ed, Australia, Cengage, pp: 173-190.

Nadia, M. (2016): Factors affecting nurses' commitment to their organization at Suez-Canal University Hospitals, Medicine Journal of Cairo University, 84(1), pp. 874-875.

Nogueras, D. (2016): Occupational commitment, education and experience as a predictor of intent to leave the nursing profession, Nursing Economic, 24(2), pp.88-89.

O'Brien-Pallas, L., \& Baumann, A. (2016): Quality of nursing work life issues-a unifying framework, Can Journal of Nursing Administration, $5(2)$, pp. 6-7.

Reyasi, H. (2013): Work life quality of nurses working in educational hospitals affiliated to Birjand university of medical sciences, Journal of Modern Care, 10(1), pp.86-87.

Rishfa, A. (2014): Quality of work life and job performance among nurses in the Tertiary Care Hospital, Maldives Nursing Journal, 41(3), p.78.

Salah, N., Mostafa, M., \& Elshahat, E. (2014) : Assessment of work stress and organizational commitment among female nurses at Zagazig University Hospitals, Middle East Journal of Applied Sciences, 4(1), p. 92.

Seyedin, H., Zaboli, R., Malmoon, Z., \& Azami, S. (2017): The relationship between ethical values and organizational commitment of staff in public and non-public hospitals, Iranian Journal of Health Sciences, 1(1), pp.4-5.

Valentine, A., Capuzzo, M. \& Guidet, B. (2013): Errors in administration of parenteral drugs in Intensive Care Units, Multinational Prospective Study, p.6.

Wilson, B. \& Laschinger, H. (2015): Staff nurse perception of job empowerment and organizational commitment, A test of Kanter's theory of structural power in organizations, Journal of Nursing Administration, 24 (4), pp. 39-40.

Zeineldin, K. \& Abdel Rahman, M. (2016): The relationship between nurses perceived pay equity and organizational commitment, life Science Journal, 10(2), p. 96

Zhao, X., Sun, T., Cao, Q., Li, C., Duan, X., Fan, L. \& Liu, Y. (2016):The impact of quality of work life on job embeddedness and affective commitment and their co-effect on turnover intention of nurses, Journal of Clinical Nursing, 22(5), pp.8-10. 